\title{
Factors Influencing the Successful Implementation of the Warehouse Management System (WMS)
}

\author{
Natesan Andiyappillai \\ Senior Business Analyst, \\ NFI Industries, \\ 2 Cooper Street, \\ Camden, NJ 08102, USA
}

\begin{abstract}
In the recent years, the increasing complexity of the logistics and supply chain business requirements have been forcing the logistics and supply chain service providers to implement and use the Warehouse Management System (WMS) effectively and efficiently to satisfy those requirements. However, only the successful implementation of a WMS could help in meeting those requirements and provide the anticipated competitive advantage in the market. Hence, this research is attempted to explore and identify the key factors that could influence the successful implementation of WMS. In this research, a case study has been conducted in a leading Logistics and Supply Chain service provider to understand and evaluate those critical factors that are contributing to a successful WMS implementation based on the actual project implementation observations and project documentations. This study is expected to help the logistics and supply chain industry in learning these key factors and take necessary actions to make the WMS implementation a very successful one for their business.
\end{abstract}

\section{Keywords}

Warehouse Management System, WMS, Logistics and Supply Chain Service Provider.

\section{INTRODUCTION}

Supply chain management is a concept that evolved in manufacturing industries in the year of 1980s. The supply chain is the management of a network of the interconnected business involved in the ultimate provision of the product and the service packages which are required by the end customers. The supply chain management can extend up to the movement and the storage of the raw materials, process inventory and the finished product from the initial point to the ending point. The supply chain management overlaps the planning and control of all the activities involved in the sourcing, procurement, conversion and all the other logistical operations. In a different sense, supply chain management integrates supply and demand management within and across companies. More recently, the loosely coupled, self-organizing network of businesses that cooperates to provide product and service offerings called as the Extended Enterprise.

A supply chain in which a sequence of steps involved to get a manufactured good or service to the consumer. The steps which include the moving and transforming of the raw materials into the finished products, transporting those products, and distributing them to the end-user. The entities involved in the supply chain include producers, vendors, warehouses, transportation companies, distribution centers, and retailers. The elements of a supply chain include all the functionality that starts with receiving an order to meeting the customer's request. These functions include product development, marketing, operations, distribution, finance, and customer service. As mentioned above, supply chain management is essential for the business process. There are many different links in this chain that require a lot of skill and knowledge. When supply chain management has gone effectively, it can lower a company's overall costs and its boost abundance. If one link breaks down means, it affects the rest of the chain and can be costly to a company. The central part of the supply chain the Warehouse. A warehouse is a vast, spacious and tenable building anticipated for business and management utilization. It functions as a storeroom place for large amounts of goods.

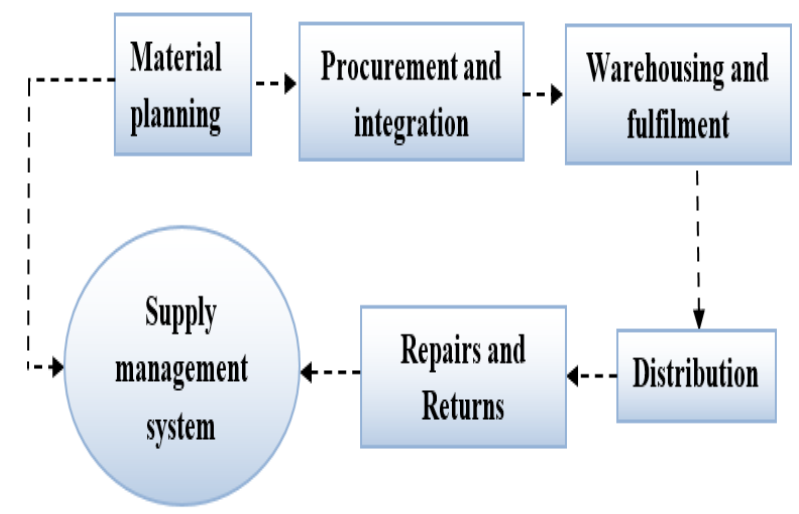

Figure: 1 Process of the Supply Management System

Figure 1 represents the Process of the supply management system. Warehousing is not merely about the storage still. It also covers the Process of the administration and manual labor required mainly for the storage and other several processes such as delivery, documentation, examination and even for the Process of the certification or grading.

Mainly there are three types of warehouses:

$$
\begin{aligned}
& \circ \text { Public Warehouses } \\
& \circ \text { Owned by the third party logistics } \\
& \circ \text { Company-owned. }
\end{aligned}
$$

The government uses this kind of the public warehouses to store shipments and contrabands they confiscated temporarily. The business sector usually resorts to company-owned to meet their storage needs. Wholesalers, exporters, importers and manufacturers are some of the standard clients of warehousing service providers. Raw materials and finished products kept in the warehouses. There are different reasons for warehousing. Mainly for storing the finished products in a bulk amount and also for the safe storage. 


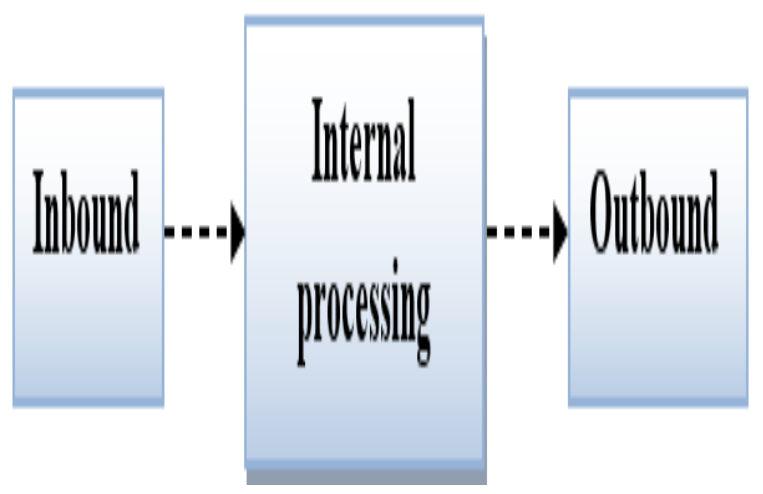

Figure: 2 The General Warehousing process

Figure 2 represents the general warehousing process. For example, the cheese making and wine and beer making industries require an extended time to produce their products because of variations in the fermentation time. So only Warehouses are the right places for their products to mature. Warehousing possibly will also cover the conclusion of goods before the Process of the distribution. The components and the packing materials get delivered to the building. The assemblage and packing of the goods will sort out in the Warehouse. By doing so, the product cover will still look new and appealing upon delivery to the distribution centers. If the packing of the goods will take place before bringing them to the Warehouse, the packaging may be damaged while on the way.

In the modern language, the distribution refers to the delivery of the finished goods to the buying centers such as shopping centers, markets and other retailer stores. Some manufacturers deliver their products directly to their recognized retailers. This is a beneficial one for the retailers because business establishments are undergone just nearby to the manufacturer's places. Direct delivery of the goods to the retailers can save from the warehousing costs. However, if the supply chain extends means due to the business nature, the warehousing cost also gets increases. Thus, it is secure to say that warehousing and sharing go hand-in-hand by providing a more cost-effective way of delivering the goods. Various warehouses utilized as a trade or transaction center even as maintaining its unique purpose.

\section{Impact of Improper warehousing and distribution:}

Major and minor mistakes similar in warehousing and delivery can result in high losses. Improper storage can damage the goods. If the damaged goods sold, they will be either be sold gets at a much lower price or else it could not be sold out. The manufacturers will acquire the loss and will not be able to get back their savings. Failure to deliver the goods to the right destination and also deliver the wrong goods will lead to the loss of business opportunities. Due to the unexpected delays, goods can get damaged, and premeditated recipients cannot accept the product or else it may incur additional losses to the business. Another adverse effect of wrong warehousing and distribution is that it can destabilize the prices of goods. If there is not enough supply due to the ineffectiveness of the warehousing and supply management, the costs of the goods may increase to meet the unaffected demand of the consumers.

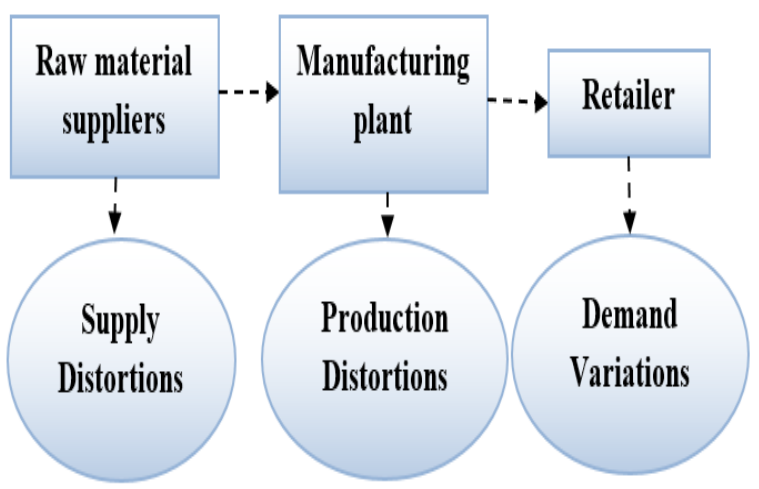

Figure: 3 Disturbances in the Supply Chain

Figure 3 represents the issues in the supply chain. It reveals that there is an essential need for the efficient monitoring of the supply chain management and the warehousing management for improving the business opportunities.

\section{LITERATURE SURVEY}

Ul-Ain et al. (2019) [1] proposed comprehensive knowledge about what has found in the domain of the B.I. system adoption, utilization and the Process of the success. A total of 111 peer-reviewed studies, covering mainly three categories which are adoption, utilization and success - published between 2000 and 2019, which were selected. The findings will present the research methods, underpinning theories and key factors employed to study B.I. system adoption, utilization and success. Besides, the review identified the key issues related to B.I. adoption, utilization and success and highlighted the areas that have attracted more or less attention. This study also suggests future directions for researchers and practitioners in terms of unexplored themes that may help organizations to obtain value from B.I. systems. Mahroof (2019) [2] proposed about the barriers and opportunities of A.I. within the Warehouse of a major retailer. The findings for this qualitative study reveal A.I. challenges resulting from a shortage of both skill and mindset of operational management, while also uncovering the opportunities presented through existing I.T. infrastructure and pre-existing A.I. exposure of management. Xu et al. (2019) [3] proposed about the fullturnover storage strategy significantly outperforms the random and class-based storage strategies. Jemelka, M., \& Chramcov, B. (2019) [4] proposed about the complex warehouse simulation to achieve effective solution. Most attention is focused on the use of recursive ABC method for warehouse management. Davis et al (2019). [5] Proposed about the information system and the neuroscience. Khan et al. (2019) [6] proposed about the strategic supply chain management system. Benjamin et al. (1995) [7] proposed an electronic markets and virtual value chains on the information superhighway. Bhagwat et al. (2007) [8] proposed about the performance measurement of supply chain management. Bititci et al. (1997) [9] proposed about an integrated performance measurement systems. Cai et al. (2009) [10] proposed an Improving Supply Chain Performance Management to Analyze Iterative KPI Accomplishment. Chan et al. (2003) [11] proposed an Innovative Performance Measurement Method for Supply Chain Management. Chan et al. (2003) [12] proposed a Conceptual Model of Performance Measurement for Supply Chains. Charan et al. (2008) [13] proposed an analysis of interactions among the variables of supply chain performance measurement systems. Chikan (2001) [14] proposed an integration of production and logistics. Chia et al. (2009) [15] proposed about the 
Performance Measurement in Supply Chain. Chin et al. (2010) [16] Proposed a model of determinants of supply chain performance in the Malaysian electronics manufacturing services (EMS) Industry.

\section{KEY FACTORS ON THE IMPLEMENTATION OF THE WAREHOUSE MANAGEMENT SYSTEM}

There are many WMS systems available in the market and customers choose them based on their business nature, complexity and ROI. In the last decade or so, below are the key technological advancements happen in this WMS implementations. And, it is very important for the service providers to understand these advancements better to implement them for being the distinct providers in the market.

1. Cloud and Warehouse Management System - The benefits of cloud-based WMS is that they allow for fast deployment, no maintenance costs, and lower I.T. costs. A cloud-based WMS can be customized to meet the unique business needs and offers additional features such as higher data security protocols for businesses that will handle highervalue inventory. Both systems are tailored to fit with the various types and sizes of the businesses. While the Cloud WMS is more ideal for medium to large size businesses as well as those with the more complexities. Irrespective of the business size gets benefits greatly varied from a WMS that increases the business efficiency and also the productivity.

2. Industry-specific blueprints - some vendors offer the industry-specific templates that leverage the proven best practices and processes for specific industries. This is expected to cut down the implementation and deployment cycle, thus reducing the implementation time and cost.

3. Integration with the ERP system - ERP and WMS integration is an important factor to consider when the business model is complex to manage and require real-time system communications. It is crucial to achieve the liveliness to make effective business decisions, becomes more competitive, and simplify the data management process.

4. Configuration and Customization - the vendors are finding out the advantage of agile approach to work as needed so that the system can easily adapt and improving its performance. The ability to easily and rapidly configure and customize a solution, in a way, is a key required element for a WMS for any business.

5. Agile Versus Waterfall implementation programs Some WMS solution providers have agile or rapid implementation programs designed to get business up and running quickly, within a restricted period of time. And, some are using the Waterfall approach based on the implementation schedule and timeline.

6. Modern UI/UX - The ease-of-use of a WMS for small businesses/SMBs can greatly reduce the system training needed, as well as make it easier to get new employees up to speed in the future.

\section{A CASE STUDY ANALYSIS}

This case study has been conducted in a leading logistics and supply chain company. The necessary information for this case study collected from the project documentation, discussions \& learnings from the expertise for analyzing the factors influencing the successful implementation of the warehouse management system. It observed that this company is operating the business at International level and also using the sophisticated I.T. Logistics systems to monitor and manage all their processes and partners. This company has been implementing Tier-1, Tier-2 and Tier-3 WMS systems at the facilities per business and customer requirements.

A decade ago, the company has seen that there is a potential growth of the Logistics business at the range of 10 to $15 \%$ a year and started to make remarkable investments in IT WMS solutions and infrastructure. A few years later, the company has started enjoying the advantages such as great improvements on the Operational efficiency which directly contribute to the cost benefits to the business by implementing the Warehouse management System. It was observed and determined that the advantages that the business are gaining due to the very successful implementation strategy and applying the lessons learned from the previous implementations. The vital factors that were evaluated and monitored very closely for every implementation for the successful delivery are listed down and explained below.

\section{Project Timeline}

- Setting up the right project timeline is very critical.

- Involves timeline for all the project activities such as WMS solution design, configuration, testing, deployment and support.

- Project planning is the critical Process the project requires warehouse resources to collect data on the physical Warehouse, materials, and inventory, as well as defining the strategies needed to operate the Warehouse.

2. WMS product expertise

- Getting the right WMS product implemented per business requirements.

- Implemented at the facilities per business and customer requirements

- WMS functionality, EDI capability, Reporting and other ancillary requirements.

\section{Business Data}

- Getting the required data and valid data from customer is critical for the entire life cycle of the implementation.

- This includes the business volume data and all the master data.

- This is not only helping the system implementation but also business planning.

\section{Training}

- Train the resources end to end, and on the work, areas get intended.

- Training happens at the Operator level, Supervisor level and Manager Level.

\section{System Audit}

- Conducting the periodic audit in the system would help identify the issues and opportunities that may find.

- Taking corrective or necessary actions based on the audit result improves the Process. 
The company has developed the below workflow or framework to monitor each WMS implementation closely.

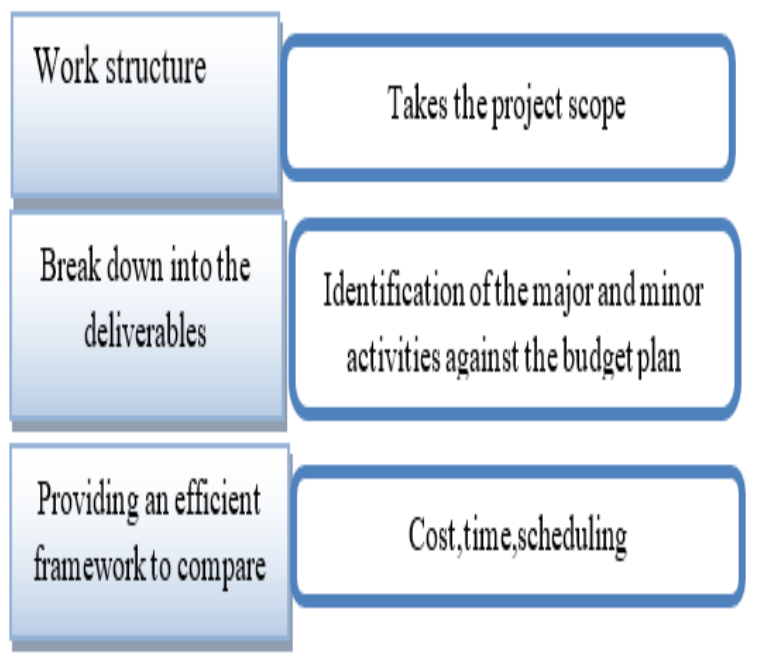

Figure: 4 Process of the Workflow

Based on these key factors, the company had overcome all the down line critical factors and can seriously enjoy the successful implementation of the warehouse management system. If it gets successfully implemented means, it can make changes to the warehouse processes in a better, faster and cheaper manner. However, the basic principle of the warehouse system has remained the same that is to provide information to allow efficient control of the movement of materials within the Warehouse.

The company had identified the key factors that were impacting the WMS implementation as detailed above, and the changes that were needed on each of these corresponding factors were researched and analyzed by the company expertise. Those were implemented in the next implementations and are detailed below;

1. Selection of the best implementation team - Project manager, Operations manager, Database administrator, EDI expert, WMS expert and Business Analysts.

2. Detail project plan and practices.

3. Collection of the warehousing data including Master and Busienss data.

4. Hands-on and necessary training be provided to the WMS users.

There are many benefits that Warehouse Management System (WMS) could bring to a business and this organization has seen the great cost savings, reduced errors and improved customer service within their business, whilst increasing the transparency across their business partners in the supply chain. And, based on the company project documentations, below are the advantages that the company enjoys after careful evaluation and monitoring the WMS implementations.

\section{Real-time Inventory Management}

Managing and controlling the inventory in the facility became very easier and real-time. This helped not just this Logistics service provider but also their customers to plan the resources and inventory accordingly.

\section{Reduced Mishandling of Inventory}

As the product is scanned for every movement at the facility, including inbound receiving, Outbound processing, Inventory control and other system driven activities, it reduced the mishandling of the inventory greatly.

\section{Efficient Returns Process}

Managing and handling the customer returns became easier and efficient, since it tracks the returned inventory at the detailed level. And, this goes back to Customer for accurate payment processing.

\section{Faster Product Delivery}

In today's competitive and dynamic environment, more and more customers do expect the service providers with better, faster and cheaper service. Hence the successful implementation of the WMS will lead to faster product delivery and this company has started realizing these on their business.

\section{Improved Customer Satisfaction}

As WMS helps to track the inventory closely at the facility, it helps the customer to work with the service provider seamlessly. And, when WMS is integrated with the Customer system, it automates all the communication between the partners electronically.

Table: 1 Results summary

\begin{tabular}{|c|c|c|}
\hline $\begin{array}{c}\text { Evaluated } \\
\text { factors }\end{array}$ & $\begin{array}{c}\text { Before WMS } \\
\text { implementation }\end{array}$ & $\begin{array}{c}\text { After WMS } \\
\text { implementation }\end{array}$ \\
\hline $\begin{array}{c}\text { Materials } \\
\text { traceability and } \\
\text { information }\end{array}$ & $\begin{array}{c}\text { Low traceability } \\
\text { and low inventory } \\
\text { accuracy }\end{array}$ & $\begin{array}{c}\text { Increased } \\
\text { inventory accuracy }\end{array}$ \\
\hline Picking route & Hardly random & $\begin{array}{c}\text { Best-of-breed } \\
\text { sequence and } \\
\text { optimization }\end{array}$ \\
\hline $\begin{array}{c}\text { Bureaucracy } \\
\text { level }\end{array}$ & $\begin{array}{c}\text { Manual Process so } \\
\text { high level }\end{array}$ & $\begin{array}{c}\text { An automatic } \\
\text { system so low }\end{array}$ \\
\hline $\begin{array}{c}\text { Delivery factor } \\
\text { Quality of the } \\
\text { logistics } \\
\text { operations }\end{array}$ & Vow delivery due & Accurate delivery \\
\hline $\begin{array}{c}\text { Employee } \\
\text { satisfaction }\end{array}$ & Regular & Extremely high \\
\hline $\begin{array}{c}\text { Organization and } \\
\text { standardization }\end{array}$ & Low & High satisfied \\
\hline
\end{tabular}

The table 1 represents the comparison of key factors that were evaluated before and after the successful implementation of the WMS in a recent major project.

\section{CONCLUSION}

With the ever-changing customer and business requirements, the providers have realized the importance of WMS implementations. And, the objective of this study was to understand the WMS system implementation in a logistics and supply chain service provider and evaluate the key factors that contribute to the successful implementation. In this evaluation, the key factors that have been contributing to a successful WMS implementation have been detailed out. And, the data regarding the workflow prior and after a successful implementation were analyzed through direct project 
implementation observations and documentary analysis. It is evident that after the successful implementation of the WMS system, the provider has started gaining the benefits in productivity, cost savings and employee satisfaction etc. It is believed that this research article will help the researchers and the professionals in the logistics and supply chain industry to learn these lessons and make them applicable in the future for very successful WMS implementations.

\section{REFERENCES}

[1] Ul-Ain, N., Giovanni, V., DeLone, W. H., \& Waheed, M. (2019). Two decades of research on business intelligence system adoption, utilization and success - A systematic literature review. Decision Support Systems.

[2] Mahroof, K. (2019). A human-centric perspective exploring the readiness towards smart warehousing: The case of a large retail distribution warehouse. International Journal of Information Management, 45, 176-190.

[3] Xu, T., Yang, P., \& Guo, H. (2019). Energy Efficiency Analysis on Robotic Mobile Fulfillment System. 2019 IEEE 6th International Conference on Industrial Engineering and Applications (ICIEA). doi:10.1109/iea.2019.8714923

[4] Jemelka, M., \& Chramcov, B. (2019). The Use of Recursive ABC Method for Warehouse Management. Software Engineering Methods in Intelligent Algorithms, 223-229.

[5] Davis, F. D., Riedl, R., vom Brocke, J., Léger, P.-M., \& Randolph, A. B. (Eds.). (2019). Information Systems and Neuroscience. Lecture Notes in Information Systems and Organisation.

[6] Khan, S. A. R., \& Yu, Z. (2019). Strategic Supply Chain Management. EAI/Springer Innovations in Communication and Computing. doi:10.1007/978-3-03015058-7

[7] Benjamin, R., Wigand, R., (1995), Electronic Markets and Virtual Value Chains on the Information Superhighway", Sloan Management Review, 36(2), pp. $62-72$.
[8] Bhagwat, R., Sharma, M.K. (2007), "Performance Measurement of Supply Chain Management: A Balanced Scorecard Approach. Computers \& Industrial Engineering, 53(1), pp. 43-62.

[9] Bititci, U.S., Carrie, A.S., McDevitt, L.G., (1997), "Integrated Performance Measurement Systems: A Development Guide", International Journal of Operations and Production Management, 17(6), May/June, MCB University Press, pp. 522-535.

[10] Cai, J., Liu, X., Xiao, Z., Liu, J. (2009), "Improving Supply Chain Performance Management: A Systematic Approach to Analyzing Iterative KPI Accomplishment", Decision Support Systems, 46(2), pp. 512-521.

[11] Chan, F., T., S., Qi, H.J. (2003), "An Innovative Performance Measurement Method for Supply Chain Management", Supply Chain Management: An International Journal, 8(3), pp. 209-223.

[12] Chan, F.T.S., Qi, H.J., Chan, H.K., Lau, H.C.W. Ip, R.W.L. (2003), "A Conceptual Model of Performance Measurement for Supply Chains", Management Decision, 41(7), pp. 635-642.

[13] Charan, P., Shankar, R., Baisya, R. (2008), "Analysis of Interactions among the Variables of Supply Chain Performance Measurement Systems", Business Process Management Journal, 14(4), pp. 512-529.

[14] Chikan, A. (2001), "Integration of Production and Logistics - in Principle, In Practice and in Education", International Journal of Production Economics, 69(2), pp.129-140.

[15] Chia, A., Goh, M., Hum, S.H. (2009), "Performance Measurement in Supply Chain: Balanced Scorecard Perspective", Benchmarking: An International Journal, 16(5), pp. 605.

[16] Chin, T.A., Tat, H.H., Yusoff, R.M., Rasli, A., (2010), "A Proposed Model of Determinants of Supply Chain Performance in the Malaysian Electronic Manufacturing Services (EMS) Industry" International Journal of Business and Social Sciences, 1(1), pp. 137-144. 